\title{
DICTIONARY USE BY EFL UNIVERSITY STUDENTS A CASE-STUDY AT KORÇA UNIVERSITY
}

\author{
Suela Koca \\ Department of Foreign Languages, Faculty of Education and Philology, \\ "Fan S. Noli" University, Korçë, Albania \\ spicikoca@gmail.com \\ Vasilika Pojani \\ Department of Foreign Languages, Faculty of Education and Philology, \\ "Fan S. Noli" University, Korçë, Albania \\ Email: vpojani@yahoo.com
}

Alda Jashari-Cicko

Department of Foreign Languages, Faculty of Education and Philology, "Fan S. Noli” University, Korçë, Albania aldajashari@ymail.com

\section{DOI:10.5901/mjss.2014.v5n19p74}

\begin{abstract}
:
This paper aimed at investigating English Monolingual (EMD) and Bilingual Dictionary (EBD) used among second and third year students of the Foreign Language Branch, Faculty of Education and Philology at "Fan S. Noli" University of Korça. We wanted to discover the students' habit and attitude in EMD and EBD use; the frequency of dictionary use, their knowledge with regard to the language learning resources available in both types of dictionaries; their skill and difficulties in using them, the reasons for referring to them, and to discover whether they received any formal instruction in dictionaries use during their English language learning. This study also surveyed students' favorite dictionaries and the reasons for their preferences.
\end{abstract}

Key words: English monolingual dictionary (EMD), English bilingual dictionary (EBD), attitude, vocabulary, learning resources, context, definition, ambiguity, equivalent

\section{Introduction}

In the process of English language learning, all learners need to possess a wide range of word knowledge, good lexical competence and extensive knowledge on English language vocabulary. A well-developed knowledge of vocabulary assists EL learners to comprehend, communicate and be successful in language acquisition. Among the wide variety of ways in vocabulary learning, either intentional or incidental, the use of dictionaries in FL learning has been and will remain a useful strategy and an important tool in the hands of the students to provide a quick and direct access to the mastering of the unknown words in particular, and of the English vocabulary in general. They provide reliable references and sources of information about words which are crucial for language learning. Walz and Cubillo state; "Dictionaries provide learners with useful linguistic and cultural information, especially when teachers are unavailable and learners are responsible for their own learning" (Walz, 1990; Cubillo, 2002). While Marckwardt (1973), comments; "Dictionaries often supply information about the language not found elsewhere. Dictionaries often supply information about grammar, usage, status, synonym discrimination, application of derivative affixes, and distinctions between spoken and written English not generally treated in textbooks, even in a rudimentary fashion" (cited in Bensoussan, Sim and Weiss, 1984: 263). Laufer (1990), similarly, believes that when word looks familiar but the sentence in which it is found or its wider context makes no sense at all, the learner should be encouraged to consult a dictionary (p.154).

According to Wright (1998), the dictionary is indeed one of the most readily accessible, most commonly used, and cheapest learning resources. It is a mine of information for language learners, providing them with knowledge about vocabulary, ranging from the most important things such as meaning, pronunciation, parts of speech, collocation and structure, to 
detailed information such as etymology and register (Nakamura, 2000). Its role does not stop at supplying information about vocabulary, but extends to assisting language learners in the comprehension and production of the text (Nation, 2001, $p$. 283). As for Wang (2007) "dictionaries for a foreign language learner are just maps in a tourist's hand. A language learner has to know how to use a dictionary..." (p.15). Wang (2007:18) also refers to Summers (1988), who concludes that dictionaries can help students learn words because they: a) present a powerful analytic tool in the organizing language, 2) provide differentiation from other similar words, which are necessary for accurate comprehension, 3) help fix new vocabulary in the memory by drawing the user's attention to opposites or words with close meaning.

But, English language learners often ask their teachers about the kind of dictionary they should use in vocabulary learning and acquisition. It is not easy to answer such question because there are various factors that determine the type of dictionary in the process of language learning. There has been much debate on which dictionary is more suitable and beneficial but in this paper we would like to focus on the learners' use of monolingual and bilingual dictionaries and their effect on vocabulary learning.

\section{Monolingual and bilingual dictionary use, literature review}

A number of studies have been conducted in regard to the use of monolingual and bilingual dictionaries. A monolingual dictionary provides detailed and precise information about the words in the second language. From the English Monolingual Dictionary (EMD), students can learn many aspects of the English language, such as the meaning of words and phrases, spelling and pronunciation, word stress, words' part of speech, grammatical information about the word, the use of target word in context, its synonyms and antonyms, the register of the word etc. Berwick and Horsfall (1996) state "when used appropriately, the EMD can be a valuable learning resource for the ESL/EFL learners". Stein (1989) notes that EFL monolingual dictionaries "include explanations of meanings, specification of a word's grammatical behavior and the illustration of meaning and the syntactical use of a word with real language examples". EMD can also help learners to work independently and think in English. Boxer (1980) as cited in Hayati \& Akram, (2006) claims that a MD not only demonstrates definitions but it also promotes fluency by offering definitions in context. Furthermore, Bejoint (1981) quoted in Scholfield, (1982) mentions that "those learners who use monolingual dictionaries would help them to get into the habit of thinking in the target language" Scholfield, (1982, p. 22).

But there are some drawbacks on the use of monolingual dictionaries. So, Thompson (1987) and Wingate (2002) as cited in Lew $(2004$, p. 4) argue that monolingual dictionaries have some limitations such as the definitions may be too difficult to understand, learners may pass over important information such as semantic restrictions of words, because they are not able to understand the basis of words and the grammatical structure can be complex. According to Yorio (1971) and Bensoussan et al. (1984), as cited in Hayati (2006, p. 126) MD-s often force students to guess and predict the meaning, and lead to doubt and confusion. They are likely to give a long and confusing description that might not suggest the intended and desired meaning.

A bilingual dictionary (BD) involves providing equivalents to the lexical units of one language by the lexical units of another language i.e. "coordinate with lexical units of one language those lexical units of another language which are equivalent in their lexical meaning." (Zgusta, 1971: 274). The use of BD has also been the focus of study for many researchers, too. Thompson, (1987) compares monolingual and bilingual dictionaries and concludes that "for learners below the level of advanced, the bilingual dictionary can do all the useful things that the monolingual dictionary can do; and it can do several of the things in a more efficient and more motivating way." (p. 286). According to Luppescu \& Day's investigation (1993: 263 ) it has come out that BD-s may have a beneficial effect on vocabulary learning despite some trade-offs. Yorio (1971) and Bensoussan et al. (1984), as cited in Hayati (2006, p. 126) note "that BD-s seem to give students security of concrete answers". They offer valid support for comprehension and production; they are time-saving, straightforward and easy to use by students and users. But they also have some deficiencies. Wingate (2002; p. 24, as cited in Lew, 2004, p. 9) states that BD-s reinforce the learners' tendency to translate from native language and, by encouraging translation; they discourage learners from thinking directly in the foreign language. The translation equivalents may not be appropriate in certain situations and might cause confusion and ambiguity. They also do not help learners to develop their academic skills such as paraphrasing, and they give little information about semantically related words such as sense relations (synonyms, antonym, heteronyms, etc).

However, the role of dictionaries in EFL learning as sources of words and information about words is irreplaceable and unequal. They are effective tools at the hands of the FL learners to take control of their learning and to better acquire and produce new language. 
Method of study

A total number of 40 second and third-year English Language students of "Fan S. Noli" University participated voluntarily in this study. They have been studying English as a foreign language for at least 6 to 7 years (including the years of study at the high school) and they are in the advanced level with a relatively good proficiency. As the aim of this study is to reveal how Albanian students of English use their monolingual and bilingual general English dictionaries, the use of a questionnaire is believed to be a helpful instrument for this purpose. The models of Tomaszczyk's (1979), Yesun Ryu's (2006) and Arafat Hamouda's (February 2013) questionnaires were modified to fulfill the aim of this study.

The questionnaire consisted of two parts with a list of statements regarding issues on EMD and EBD, students' habit and attitude to their use, students' knowledge about the language learning resources available in both dictionaries, students' skills and difficulties in using them, as well as their favorite dictionaries and reasons for their preferences. Respondents were asked to choose the statement that they think is the appropriate one.

The first section of the questionnaire provides information about the respondents' interaction with the dictionary and their habit in using the dictionary, the second part analyzes dictionary use and their type, students' attitude about their usefulness, the kind of information they receive and difficulties in using a dictionary.

The questionnaire was administrated during the Text Analysis classes. Before its completion, students were well informed and instructed about the questionnaire and the aim of the study. The statements were rated according to the "Yes" or "No" alternatives or "Agree" or "Disagree" answers. The questionnaire results for the items questioned were calculated and then converted in percentage to give clearer results for the readers. The version of the questionnaire was given at the appendix by the end of the study.

Results

Part I -- Students' habits and attitude to dictionary use

Table 1/a

1 Have you got a dictionary?

2 Do you use the dictionary at school?

3 Do you use the dictionary at home?

4 Do you think the dictionary is useful?

5 Have you ever been taught how to use the dictionary?

6 Who recommended the dictionary you have?

\begin{tabular}{|c|c|c|c|}
\hline Yes & & No & \\
\hline Nr. & $\%$ & Nr. & $\%$ \\
\hline 40 & $100 \%$ & - & - \\
\hline 19 & $47.5 \%$ & 21 & $52.5 \%$ \\
\hline 40 & $100 \%$ & - & - \\
\hline 40 & $100 \%$ & - & - \\
\hline 21 & $52.5 \%$ & 19 & $47.5 \%$ \\
\hline Teacher & $\begin{array}{l}\text { Bookshop } \\
\text { assistant }\end{array}$ & Parents/friends & $\begin{array}{l}\text { Searching } \\
\text { the Inter. }\end{array}$ \\
\hline 24 & 1 & $3 / 2$ & 10 \\
\hline
\end{tabular}

Table 1/a presents the answers to a yes or no question about whether the respondents owned a dictionary and used it at school or at home. It resulted that all of them (40) had at least one dictionary and used it mostly at home. As for its use at school, the data show that only half of them (19/47.5\%) happened to use it at school. This indicates that students may acquire the information they seek for from their English language teachers in their English classes. When asked about the importance of the dictionary use, they all were of the opinion that its possession and use is vital for everyone who wants to learn English but a considerable number of them (19/47.5\%) were not given any instruction on how to use it. In addition, only $24 / 60 \%$ of them took into consideration their teacher's recommendation for their dictionary purchasing. This again reinforces the fact that almost half of the students (19) have not taken any lessons on how to use the dictionary from their English teachers.

Table $1 / \mathrm{b}$ 
Favorite type of dictionaries

1 What type of dictionaries have you got?

\begin{tabular}{llll}
\hline Nr. & $\%$ & $\mathrm{Nr}$. & $\%$ \\
32 & $80 \%$ & 14 & $35 \%$ \\
29 & $72.5 \%$ & 11 & $27.5 \%$
\end{tabular}

2 Do you prefer a bilingual or monolingual dictionary?

Regarding the type of dictionary the respondents preferred, it was found that the majority of them $(29 / 72.5 \%)$ liked to use a monolingual dictionary to bilingual one. This finding explains the importance the monolingual dictionary has "in helping students to get into habit of thinking in the target language" as Bejoint (1981) quoted in Scholfield (1982). It incites students to think and predict the meaning of the unknown word.

Part II Types of dictionaries regarding language

Table 1/a Agree Disagree

\begin{tabular}{lll|ll|l} 
& & Nr. & $\%$ & Nr. & $\%$ \\
2 & I like to use a monolingual dictionary & 29 & $72.5 \%$ & 11 & $27.5 \%$ \\
\hline 3 & I like to use the Albanian-English bilingual dictionary & 37 & $92.5 \%$ & 3 & $7.5 \%$ \\
& & 27 & $67.5 \%$ & 13 & $32.5 \%$
\end{tabular}

In response to what type of bilingual dictionary they prefer to use, 37 out of 40 students (92.5\%) answered that they liked to use the English-Albanian dictionary. It was believed to be easier and more practical to use, offering comprehension security (competence) to students in general, whereas the Albanian-English dictionary was less used by them (67.5\%). (It was found that the majority of students preferred the English-Albanian bilingual dictionary over the Albanian-English one)

Table 1/b Types of dictionaries regarding format

1 I use Paper dictionary

2 I use Electronic dictionary

3 I use Online dictionary

4 I use small pocket booklet non-electronic dictionary

5 I use pocket electronic dictionary

\begin{tabular}{l|ll|l} 
Nr. & $\%$ & Nr. & $\%$ \\
36 & $90 \%$ & 4 & $10 \%$ \\
26 & $65 \%$ & 14 & $35 \%$ \\
18 & $45 \%$ & 22 & $55 \%$ \\
14 & $35 \%$ & 26 & $65 \%$ \\
16 & $40 \%$ & 24 & $60 \%$
\end{tabular}

Nowadays, dictionary users can find them in a variety of formats. Asked what type of dictionary they mostly used, it was noted that the most popular type that topped the list was paper dictionary (36/90\%) and the least used was pocket booklet non-electronic dictionary (14/35\%). Compared to online dictionary, the use of electronic dictionary came the second after the paper dictionary; more than half of the students (65\%) would use them. This may be due to the fact that our students could find and purchase paper dictionary easier than electronic dictionary. However, about half of the subjects (18/45\%) preferred to use Online dictionary, this because of its fast and easy way in use and the access they could have on the Internet.

Table 1/c Dictionary use for different language activities

1 I use the dictionary when reading an English text

2 I use the dictionary during or after listening

3 I use the dictionary when I want to write in English

4 I use the dictionary when I speak or want to speak in English
Nr.

\begin{tabular}{l|ll} 
Nr. & $\%$ & Nr. \\
38 & $95 \%$ & 2 \\
15 & $37.5 \%$ & 25 \\
33 & $82.5 \%$ & 7 \\
8 & $20 \%$ & 32
\end{tabular}

$\%$
$5 \%$
$62.5 \%$
$17.5 \%$
$80 \%$


5 I use the dictionary to translate from Albanian into English or from 37 English into Albanian

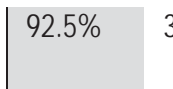

7.5\%

Table 1/c presents how much the dictionary was used concerning language skills such as reading, listening, writing, speaking and translation. According to the data obtained from this table, it resulted that the respondents (38/95\%) mostly consulted dictionary for reading purposes as it is considered to be one of the most important language activities. The frequency of dictionary use for translation purposes (37/92.5\%) occupied the second place followed by writing (33/82\%) and then by listening (15/37.5\%) and the dictionary use for speaking activities is rated the last (8/20\%).

Table 1/d Kind of information you look up in your dictionaries

1 I use a dictionary to look up the meaning of a word or a phrase.

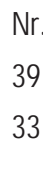

3 I use a dictionary to check for collocation

$4 \quad$ I consult a dictionary when I want to know the pronunciation of a vocabulary item

5 I use a dictionary for synonyms

6 I use a dictionary to check spelling

7 I use a dictionary to look up antonyms

8 I use a dictionary to find out whether a word is in common usage

9 I use a dictionary to find out what 'part of speech' a word is or the derivations of such vocabulary items

10 I use a dictionary to check the grammatical function/ structure of a 18 vocabulary item

\begin{tabular}{l|ll|l} 
Nr. & $\%$ & Nr. & $\%$ \\
39 & $97.5 \%$ & 1 & $2.5 \%$ \\
33 & $82.5 \%$ & 7 & $17.5 \%$ \\
32 & $80 \%$ & 8 & $20 \%$ \\
32 & $80 \%$ & 8 & $20 \%$ \\
31 & $77.5 \%$ & 9 & $22.5 \%$ \\
30 & $75 \%$ & 10 & $25 \%$ \\
29 & $72.5 \%$ & 11 & $27.5 \%$ \\
22 & $55 \%$ & 18 & $45 \%$ \\
20 & $50 \%$ & 20 & $50 \%$ \\
18 & $45 \%$ & 22 & $55 \%$ \\
& & & \\
\hline 14 & $35 \%$ & 26 & $65 \%$
\end{tabular}

Table $1 / \mathrm{d}$ gives information looked up in the dictionary. Finding the meaning of a word was noticed to be the most lookedup information. This answer was given by almost all respondents (97.5\%) and seems to be the same with the results of other studies on the dictionary use (Tomaszczyk, 1979; Bejoint, 1981). Consulting dictionary for the examples the new word is used in followed the meaning of the word (82.5\%), and then came pronunciation and collocation at a rate of $80 \%$. This finding highlighted the fact that pronunciation remains an important aspect in English language acquisition and students will always be in need of a dictionary to look for it. Synonyms, spelling, antonyms, common usage, derivation, grammatical function and etymology of new word were rated as it follows: 31 subjects out of $40(77.5 \%)$ looked up a word for its synonym; it showed that respondents did not have good command on them; spelling occupied the fourth place in the bulk of information looked up (75\%) followed by antonyms at a rate of $72.5 \%$. Almost half of the students (50-55\%) consulted the dictionary to gain information on the common usage and word formation of the word. While grammatical function and word etymology were not much looked up by the respondents (45\%-35\%) because the information students have acquired might have been gained either from other books or from their teachers.

Table 1/e Difficulties in dictionary use (while using)

1 I cannot find the word sought.

2 It is difficult to find the information I want.

3 It is difficult to identify the right meaning in a polysemous word.

4 It is difficult to understand the definition.

5 I cannot use the dictionary whenever I want.

\begin{tabular}{l|ll|l} 
Nr. & $\%$ & Nr. & $\%$ \\
15 & $37.5 \%$ & 25 & $62.5 \%$ \\
13 & $32.5 \%$ & 27 & $67.5 \%$ \\
22 & $55 \%$ & 18 & $45 \%$ \\
7 & $17.5 \%$ & 33 & $82.5 \%$ \\
21 & $52.5 \%$ & 19 & $47.5 \%$
\end{tabular}


7 The information I found in the dictionary is insufficient.

13

7 It takes too much time to consult the dictionary.

8 Too few examples

9 Unclear examples

10 Failure to understand the pronunciation information

\begin{tabular}{l|ll}
13 & $32.5 \%$ & 27 \\
19 & $47.5 \%$ & 21 \\
16 & $40 \%$ & 24 \\
7 & $17.5 \%$ & 33 \\
8 & $20 \%$ & 32
\end{tabular}

$67.5 \%$

$52.5 \%$

$60 \%$

$82.5 \%$

$80 \%$

The results of students' difficulties while using a dictionary are given in Table 1/e. More than half of the respondents (55\%) reported that they could not identify the right meaning in a polysemous word. This finding agrees with the study of Al-Fuhaid (2004), who found that his Saudi university students had difficulties in identifying the right meaning of a word within an entry. Another problem in dictionary use for our students was that they $(52.5 \%)$ could not use it whenever they wanted (this might be for the inconvenience paper dictionary has in carrying it) and $47.5 \%$ of them were of the opinion that it takes much time to look up words in a dictionary. 16 out of 40 students (40\%) considered the presence of few examples as one of the difficulties they encounter while using a dictionary. $32 \%-37 \%$ of the students reported that they had difficulties in finding the information they were looking for or in finding the right word being sought. But for a few number of students (7-8/17; 5\%-20\%) the examples and pronunciation information were unclear. Rated at the bottom of the list, unclear examples and failure to understand pronunciation showed that they were not regularly encountered by the students and had a low level of difficulty for them.

Table 2/ a The purpose of using MD or BD MDBD

1 To understand an English word, e.g. during reading

2 To find Albanian equivalent for an English word, e.g. for translation

3 To check on how to use an English word that you already know, e.g., $\quad 25$ during writing in English

\begin{tabular}{l|ll|l} 
Nr. & $\%$ & Nr. & $\%$ \\
29 & $72.5 \%$ & 11 & $27.5 \%$ \\
12 & $30 \%$ & 28 & $70 \%$ \\
25 & $62.5 \%$ & 15 & $37.5 \%$
\end{tabular}

Asked about the purpose of using a MD or $\mathrm{BD}$, it was revealed that respondents preferred to use the MD either to understand a word while reading or to check how to use it in writing (72.5\%-62.5\%). BD was mainly used for translation.

Table $2 / \mathrm{b}$ The frequency of using MD or BD

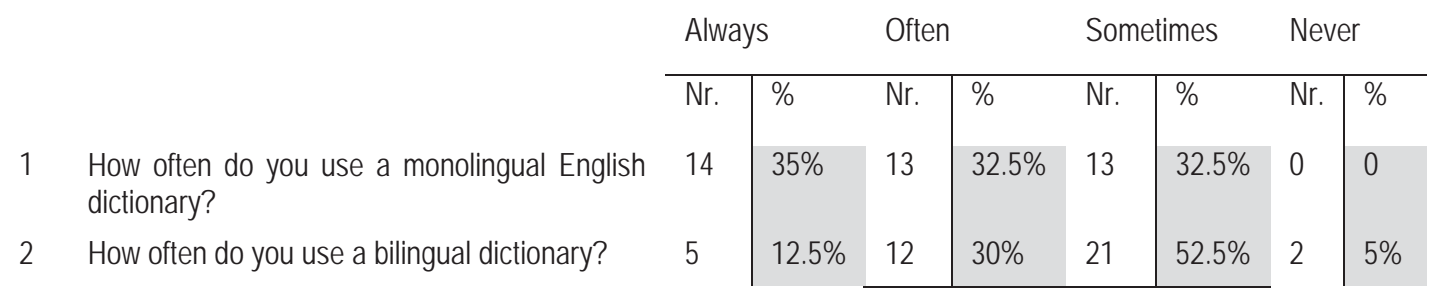

Research findings showed that a monolingual dictionary was overused compared to bilingual one in terms of frequency. $67.5 \%$ (27 out of 40 ) of the students used the monolingual dictionary always or often while a bilingual dictionary was used at a rate of $42.5 \%$. More than half of the subjects (52.5\%) declared that it was used only sometimes. Although the difference in the number of students using monolingual to bilingual dictionary was not a big one (great), it again highlighted what Baxter has stated. According to him a monolingual dictionary not only creates an impression that there is always an alternative way to express a lexical item by definition, but it also gives a language learner the practical means to do so (Baxter, 1980, p. 334). This in turn develops learners' fluency as when they get used to the alternative method of providing definitions, they will no longer encounter problems when seeking a certain lexical item (Baxter, 1980, p. 330). This finding might also be based on the argument that the respondents are actually in the advanced level of studies and have already passed that period of study when they preferred to use the bilingual dictionary. 


\section{Conclusion}

This paper aimed at identifying the type (EMD and EBD) of dictionary used by our EFL students, their preferences, attitude, frequency and difficulties in their use, the language information looked up and the formal training they had taken on the dictionary use. Though there might be some limitations on the research findings because of students' level of English language proficiency, it was revealed that:

almost all students owned one or more than one MD or BD from which they preferred the monolingual one although they uniformly were aware of dictionary usefulness, half of them (52.5\%) disagreed to have received any formal training on their use

$60 \%$ of the respondents based their decision to purchase a dictionary on the recommendation of their English teacher all students admitted that dictionary was much more used at home than in English classes

in terms of language, $92.5 \%$ of the students favored the use of English-Albanian bilingual dictionary over Albanian-English language

regarding dictionary format, paper dictionary was the most frequently used (90\%) followed by electronic dictionary (65\%) and online dictionary which was used by a considerable number of students (45\%). The least used dictionary was revealed to be the small pocket non-electronic dictionary at a rate of $35 \%$.

reading English texts was the main language activity which required frequent dictionary use by $95 \%$ of the respondents, followed by translation activity (92.5\%) and writing activity by $82.5 \%$. The least frequent use of a dictionary was when students were asked to speak in English (8 out of 40 or $20 \%$ ).

Among the 11 items of information students looked up in the dictionary, was the meaning of the word (97.5\%) followed by examples (82.5\%), pronunciation and collocation (80\%), synonyms (77.5\%), spelling (75\%) and antonyms (72.5\%). Only a small number of students (35\%) consulted a dictionary for etymology.

students encountered some difficulties while using a dictionary. Finding the right meaning of a word topped the list of difficulties (55\%). About half of them (21 st.) found it difficult to use a dictionary whenever they wanted or much time consuming (19 st.).

MD was mainly used to find the meaning of a word and its use while BD was used for finding the word equivalent in L2.

MD use prevailed BE use at a rate of respectively $67.5 \%$ versus $42.5 \%$

\section{Bibliography}

Al-Fuhaid, M. (2004). Vocabulary learning strategies: an empirical study of their use and evaluation by Saudi EFL learners majoring in English. Unpublished PhD. thesis, University of Durham. Vol.1, No.1; February 2013

Baxter, J. (1980). The dictionary and vocabulary behavior: a single word or a handful? TESOL Quarterly, 14, 325-336.

Béjoint, H. 1981. The foreign student's use of monolingual English dictionaries: a study of language needs and reference skills. Applied Linguistics 2, 207-222.

Bensoussan, M., Sim, D. and Weiss, R. (1984).The effect of dictionary usage on EFL test performance compared with student and teacher attitudes and expectations.

Berwick, G. \& Horsfall, P. (1996). Making Effective Use of the Dictionary. London: Centre for Information on Language Teaching and Research.

Hayati, A. M. \& Fattahzadeh. (2006) The effect of monolingual and bilingual dictionaries on vocabulary recall and retention of EFL learners. The Reading Matrix, 6(2-6), Sept 2006

Holley, F.M. (1973). A study of vocabulary learning in context: the effect of new-word density in German reading materials. Foreign Language Annals. 6: 339-47 Language Learning. 43/2: 263-87.

Laufer, B. (1990). Ease and difficulty in vocabulary learning: some teaching implications. Foreign Language Annals. 23/2: $147-55$.

Lew, R. (2004). Which dictionary for whom? Receptive use of bilingual, monolingual and Semi-bilingual dictionaries by Polish learners of English. Published Ph.D. thesis, Published by motive Poznan, Poland. 
Luppescu, S. \& Day, R.R. (1993). Reading, dictionaries and vocabulary learning. Language learning. 43: 263-287

Luppescu, S. and Day, R. R. (1993). Reading, dictionaries, and vocabulary learning.

Nakamura, T. (2000). The use of vocabulary learning strategies: the case of Japanese EFL learners in two different learning environments. PhD thesis, University of Essex.

Nation, I. (2001). Learning vocabulary in another language. Cambridge University Press Reading in a Foreign Language. 2: 262-76.

Scholfield, P. (2005) Why shouldn't monolingual dictionaries be easy to use as bilingual ones? Retrieved December 23, 2010 from http:www.pearsonlongman.com/Dictionaries/pdfs/Mono-Biolingual.pdf

Stein, G. (1989). Recent developments in EFL dictionaries. In M.L. Tikoo (Ed.) Learner's dictionaries: state of the Art. Singapore. SEAMEO Regional Language Center.

Summers, D. (1988). The role of dictionaries in language learning. In R. Carter \& M. McCarthy (Eds.), Vocabulary and language teaching: 111-125. London: Longman

Walz, J. 1990 The dictionary as a Secondary Source in Language Learning. The French review 64 (1), 79-94

Wang, M. H. (2007) The effects of dictionary skills instruction on reading comprehension of junior high EFL students in Taiwan. Unpublished Master Thesis, National Sun Yat-sen University. Zgusta, L. (1971). Manual of lexicography. Praha, Academia. (p.15).

Wright, J. (1998). Dictionaries: Resource books for teachers. Oxford: Oxford University Press.

Zgusta, L. (1971). Manual of lexicography. Praha, Academia.

\section{Appendix Questionnaire}

Part I -- Students' habits and attitude to dictionary use

This questionnaire is about English Dictionaries' (either monolingual or bilingual) use in language learning. It aims to collect information on general knowledge about the types of dictionaries and investigate the attitudes and skills in using them, the reasons for their use, the difficulties and the favorite type of dictionary.

- Have you got a dictionary? YesNo

- What type of dictionaries have you got? MonolingualBilingual

- Do you prefer a bilingual or monolingual dictionary? MonolingualBilingual

- Do you like paper or electronic dictionary? PaperElectronic

- Who recommended the dictionary you have?

your teacherthe bookshop assistant your parents a friend by searching the internet

- Do you like to use a dictionary?YesNo

- How often do you use it?

frequentlyrarely 3-5 times a week once a week never everyday

- Do you use the dictionary at school?YesNo

- Why do you use the dictionary at school?

- Do you use the dictionary at home?YesNo

- Why do you use the dictionary at home? (homework, preparation, study for exam, read stories, library, etc.) 
- What are the skills you use the dictionary for?

readingwritinglisteningspeaking

- Do you think the dictionary is useful? YesNo

- Have you ever been taught how to use the dictionary? Yes No

\section{Part II Agree Disagree}

Types of dictionaries regarding language

I like to use a monolingual dictionary

I like to use the English-Albanian bilingual dictionary

I like to use the Albanian-English dictionary

Types of dictionaries regarding format

I use Paper dictionary

I use Electronic dictionary

I use Online dictionary

I use small pocket booklet non-electronic dictionary

I use pocket electronic dictionary

Frequency of dictionary use for different language activities

I use the dictionary when reading an English text

I use the dictionary during or after listening

I use the dictionary when I want to write in English

I use the dictionary when I speak or want to speak in English

I use the dictionary to translate from Albanian into English or

from English into Albanian

Kind of information you look up in your dictionaries

I use a dictionary to look up the meaning of a word or a phrase.

I use a dictionary for synonyms (similar words).

I use a dictionary to look up antonyms (the opposites).

I use a dictionary to check spellings

I consult a dictionary when I want to know the pronunciation of a vocabulary item.

I consult a dictionary when I want to see some examples about the uses of a certain word.

I use a dictionary to find out what 'part of speech' a word is (i.e., n., v., adj., etc.) or the derivations of such vocabulary items.

I use a dictionary for etymology.

I use a dictionary to find out whether a word is in common usage.

I use a dictionary to check for collocation, i.e., words and phrase that go with a vocabulary item

I use a dictionary to check the grammatical function/structure of a vocabulary item.

The difficulties in dictionary use

Difficulties while using dictionary

I cannot find the word sought.

It is difficult to understand the definition. 
It is difficult to identify the right meaning in a polysemous word.

It is difficult to find the information I want.

I cannot use the dictionary whenever I want.

The information I found in the dictionary is insufficient.

It takes too much time to consult the dictionary.

Too few examples

Unclear examples

Failure to understand the pronunciation information

The purposes of using MD or BD

1. What kind of dictionary would you normally use for each of the following purposes?

1) To understand an English word, e.g. during reading

English monolingual Bilingual

2) To find Albanian equivalent for an English word, e.g. for translation

English monolingual Bilingual

3) To check on how to use an English word that you already know,

e.g., during writing in English

English monolingual Bilingual

4) Other (please specify)

English monolingual Bilingual

5) How often do you use a monolingual English dictionary?

always often sometimes never

6) How often do you use a bilingual dictionary?

always often sometimes never 